\title{
Maternal dietary iron intakes during the first trimester of pregnancy
}

\author{
E. Fox ${ }^{1}$, S. Cawley ${ }^{1}$, A. Brennan ${ }^{1}$, L. Mullaney ${ }^{1}$, D. McCartney ${ }^{1}$ and M.J. Turner ${ }^{2}$ \\ ${ }^{1}$ School of Biological Sciences, Dublin Institute of Technology, Dublin 8, Republic of Ireland and ${ }^{2} U C D$ Centre for \\ Human Reproduction, Coombe Women and Infants University Hospital, Dublin 8, Republic of Ireland
}

Iron requirements rise in pregnancy due to the volaemic expansion and increased red cell mass needed to support optimal fetal and placental development ${ }^{1}$. The Irish RDA for iron in pregnancy is $15 \mathrm{mg} / \mathrm{day}^{2}$. There is a paucity of Irish data focusing on iron intakes in pregnant women.

This aim of this observational study was to examine maternal dietary iron intake in the first trimester.

Women were recruited at their convenience in January 2014 after sonographic confirmation of a singleton pregnancy in the first trimester. Maternal weight and height were measured and BMI $\left(\mathrm{kg} / \mathrm{m}^{2}\right)$ was calculated. Maternal diet was assessed using a supervised 4-day retrospective food diary (FD) (including two weekend days) in combination with a food frequency questionnaire (FFQ). Dietary analysis was carried out using the nutritional software package Nutritics version 3.7 University Edition which was designed to include the most up-to-date nutrient values for fortified foods. The food composition database was used to calculate daily energy and iron intakes. Black's equation was used to exclude under-reporters $(n=48 / 125)^{3}$.

Of the 125 women recruited, mean maternal BMI was $26.0 \mathrm{~kg} / \mathrm{m}^{2}( \pm 5 \cdot 4)$, with $20.8 \%$ obese. Mean maternal age was $30 \cdot 1$ years $( \pm 5.5)$. Of the plausible reporters, the mean (SD) dietary iron intake observed was $12.4( \pm 4.2) \mathrm{mg}$. Forty three percent (33/77) had a dietary iron intake below the estimated average requirement of $10.8 \mathrm{mg}$. Of these women, only $26 \%(20 / 77) \mathrm{met}$ the RDA of $15 \mathrm{mg} / \mathrm{day}$. On univariate analysis, the strongest predictor of dietary iron intake was planned pregnancy $(13.3 \mathrm{mg} \pm 4.45 \mathrm{versus} 11.15 \mathrm{mg} \pm 3.57 \mathrm{in}$ planned versus unplanned pregnancy respectively) $(p=0.02)$.

This study suggests that nearly half of the pregnant women in Ireland have dietary iron intakes below recommended levels and only one in five women are meeting the recommended daily amounts. Low maternal dietary iron intakes impacts on foetal development ${ }^{1}$. This highlights the importance of educating women of childbearing age about the inclusion of dietary sources of iron. These findings should also inform future Irish public health policies in relation to iron supplementation in pregnancy.

1. Institute of Obstetrics and Gynaecologists \& Royal College of Physicians of Ireland (2013) Dublin.

2. Food Safety Authority of Ireland (1999) Dublin

3. Black A.E. (2000) Int J ObesRelatMetabDisord 24, 1119-1130. 